\title{
Obesity-Related Inflammation and Endothelial Dysfunction in COVID-19: Impact on Disease Severity
}

\author{
Andrea De Lorenzo (D) \\ Vanessa Estato ${ }^{2}$ \\ Hugo C Castro-Faria-Neto ${ }^{2}$ \\ Eduardo Tibirical \\ 'Instituto Nacional de Cardiologia, Rio de \\ Janeiro, RJ, Brazil; '2Laboratorio de \\ Imunofarmacologia, Instituto Oswaldo \\ Cruz, FIOCRUZ, Rio de Janeiro, RJ, Brail
}

\begin{abstract}
The coronavirus disease 2019 (COVID-19) pandemic has put into evidence another pandemic - obesity. Currently, several studies have documented the association between obesity and COVID-19 severity. The mechanisms underlying the increased risk of complications and mortality in obese patients with COVID-19 are of diverse nature. Inflammation plays a central role in obesity. Metabolic alterations seen in obese patients are related to an inflammatory response, and several studies report elevated levels of circulating inflammatory cytokines in obese patients. Also, deregulated expression of adipokines, such as leptin and resistin, increase the expression of vascular adhesion molecule 1 and intercellular adhesion molecule 1 that contribute to increased vascular leukocyte adhesiveness and additional oxidative stress. Additionally, it is now recognized that the chronic impairment of systemic vascular endothelial function in patients with cardiovascular and metabolic disorders, including obesity, when intensified by the detrimental effects of SARSCoV-2 over the endothelium, may explain their worse outcomes in COVID-19. In fact, vascular endothelial dysfunction may contribute to a unfavorable response of the endothelium to the infection by SARS-CoV-2, whereas alterations in cardiac structure and function and the prothrombotic environment in obesity may also provide a link to the increased cardiovascular events in these patients.
\end{abstract}

Keywords: obesity, inflammation, COVID-19, endothelial dysfunction, microcirculation

\section{Obesity, COVID-I 9 and Inflammation}

The coronavirus disease 2019 (COVID-19) pandemic has put into evidence another pandemic - obesity, an increasing threat to societies around the world. ${ }^{1}$ The first studies of COVID-19 did not provide body mass index (BMI) data, ${ }^{2}$ and the association between disease severity and obesity was not perceived initially. Subsequent data from several countries, however, cast light on this association, ${ }^{3,4}$ and several studies have documented the association between obesity and COVID19 severity. ${ }^{4-7}$ Currently, obesity may be considered a true independent risk factor for COVID-19 mortality. ${ }^{8}$

The mechanisms underlying the increased risk of complications and mortality in obese patients with COVID-19 are many, and of diverse nature (Figure 1). Obesity is associated with several disorders, related to defective homeostasis of the dysfunctional adipose tissue, in which local and systemic chronic inflammation, oxidative stress, altered release of cytokines, and impaired immune response play important roles $^{9-11}$; all of these have been demonstrated to be associated with

\footnotetext{
Correspondence: Andrea De Lorenzo Instituto Nacional de Cardiologia, Rua das Laranjeiras 374, Rio de Janeiro, RJ, 22240 006, Brazil

Tel +552130372288

Email andlorenzo@cardiol.br
} 


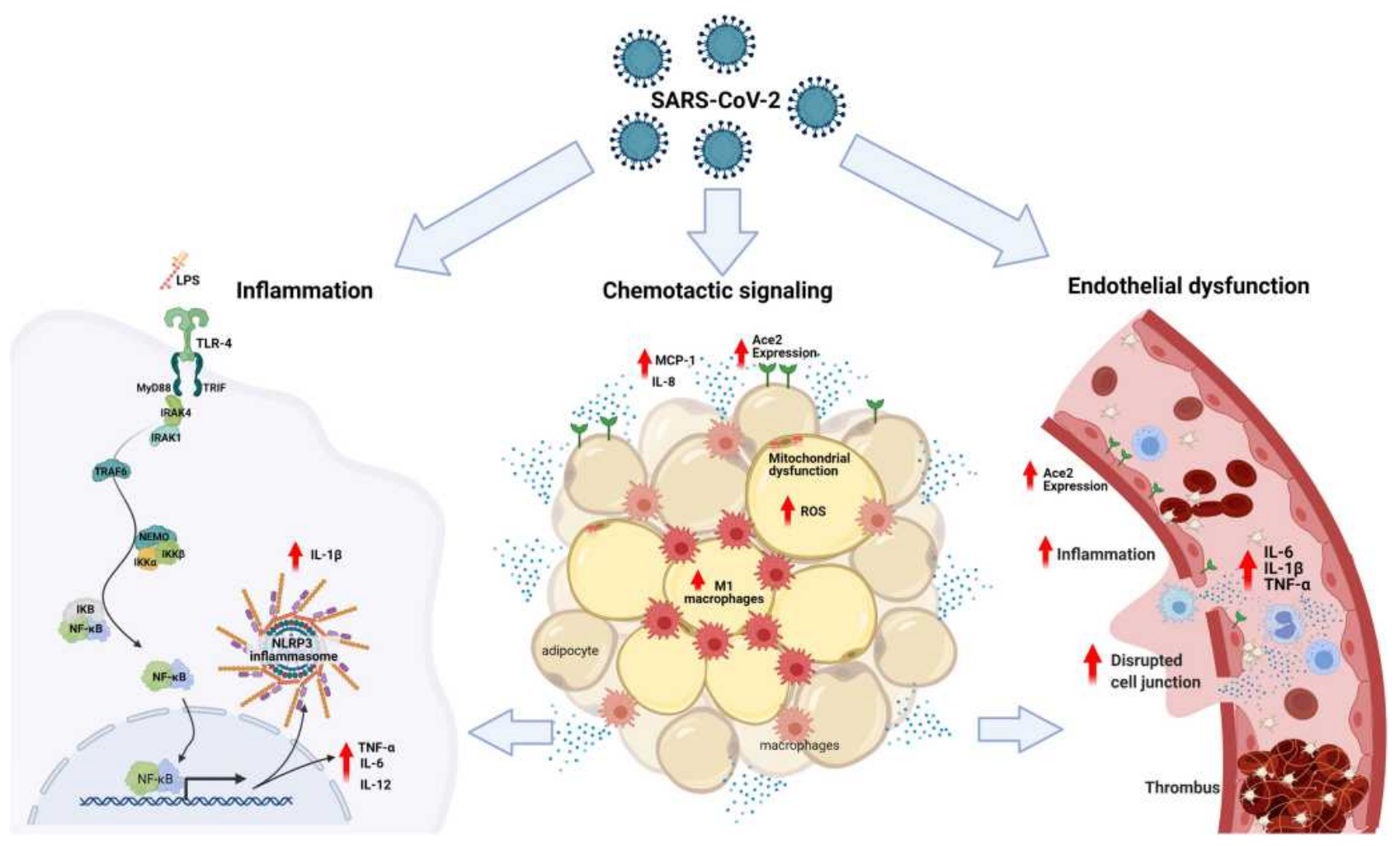

Figure I The mechanisms underlying the increased risk of complications and mortality in obese patients with COVID-19 based on the association of low-grade inflammation, adipose tissue dysfunction and endothelial dysfunction: In obese patients with COVID-19 or SARS-CoV-2, as well as, the bacterial endotoxins (LPS) of the intestinal bacterial translocation promote the activation of TLR4 in favor of the MyD88-dependent pro-inflammatory pathway. The activation of NF- $\kappa B$ is linked to the production of TNF- $\alpha$, IL-I $\beta$, IL-6, IL- I2 and other cytokines, contributing to the activation of NLRP3 inflammasomes and increased expression of ECA2. In the adipose tissue of patients with COVID-19, there is an increase in the expression of ECA2, promoting greater entry of SARS-CoV-2, making this tissue a viral reservoir. Metabolic inflammation in obese patients is characterized by dysfunctional adipose tissue, with mitochondrial dysfunction and decreased fatty acid oxidation, causing an amount of inflammatory cells showing an increase in the influx of MI macrophages and chemotactic signaling, via MCP-I and release of IL- 8 by adipocytes, associated with an increase in reactive oxygen species. Associated with this process of immune activation, obese patients with COVID-19 have systemic microvascular dysfunction and a predisposition to thrombus formation that is exacerbated by higher levels of circulating inflammatory cytokines, such as TNF- $\alpha$, IL-I $\beta$ and IL-6, worsening the outcomes in COVID-I9.

higher risk and worse prognosis of infectious diseases in this patient population. ${ }^{12-14}$

Inflammation plays a central role in obesity. ${ }^{15}$ Obesity promotes profound changes in the structure and function of adipose tissue, as adipocytes undergo hypertrophy and hyperplasia, increasing oxygen need, which remains unmet due to the insufficient vascularization relative to the enlarged adipose tissue. This leads to tissue hypoxia and immune cell infiltration that perpetuates local inflammation. ${ }^{16-18}$ Insulin resistance is also a link between obesity-related metabolic disorders and inflammation, as the remodeling of the adipose tissue leads to activation of NLRP3-inflammasome, which ultimately impairs of the insulin-signaling pathway and insulin resistance, a key factor in the development of the metabolic syndrome. ${ }^{19}$

Additionally, mitochondrial dysfunction in adipocytes may be a cause of adipose tissue inflammation and insulin resistance. The defective mitochondrial function and decreased fatty acid oxidation in adipocytes increase triglyceride accumulation, adipocyte enlargement and consequent adipose tissue hypoxia; this, in its turn, leads to accumulation of hypoxia-inducible factor-1 $\alpha$ (HIF-1 $\alpha$ ), which promotes adipose tissue inflammation and fibrosis. $^{20}$ This continuous inflammatory cycle also contributes to a neuro-immuno-endocrine dysregulation in the context of the metabolic syndrome. ${ }^{21}$ The inflammatory state affecting obese individuals is called metabolic inflammation or metainflammation, in which there is also an increased influx of M1 macrophages occurring, as well as decreased M2 macrophages and Treg cells in the visceral adipose tissue $^{22}$ through chemotactic signaling, via MCP-1 and IL- 8 released by adipocytes. ${ }^{23}$

The excessive intake of carbohydrates is an important trigger for these processes. $^{24}$ In addition, peripheral inflammation and various pro-inflammatory signals in the nucleus accumbens, including reactive gliosis, increased expression of cytokines, antigen-presenting markers and transcriptional activity of $\mathrm{NFKB}^{25}$ contribute to the 
activation of the innate immune response, mainly through activation of Toll-type receptors (TLR), specifically TLR4 , considered an intersection of dysfunctional metabolism and activated immunity in obesity. ${ }^{26} \mathrm{NF}-\kappa \mathrm{B}$ is a molecular hub for pro-inflammatory gene induction both in innate and adaptive immune responses since it is highly regulated and regulates the expression of a vast array of genes. ${ }^{27}$ Among many different immune effects, NF- $\mathrm{BB}$ activation is linked to the production of TNF- $\alpha$, IL-1 $\beta$, IL-6, IL-12 and other cytokines, and is also involved in NLRP3 inflammasome regulation and activation of $\mathrm{CD}^{+}$ T-helper cells. ${ }^{28}$ It is noteworthy that there is evidence that the virus can bind and activate TLR4 signaling in favor of the proinflammatory MyD88-dependent and contributing to increased expression of ACE2 and promoting greater viral entry. ${ }^{29}$

\section{Obesity and Vascular Endothelial Dysfunction \\ Macrovascular Endothelial Dysfunction}

The chronic impairment of systemic vascular endothelial function in patients with cardiovascular and metabolic disorders, including hypertension, obesity, diabetes mellitus, coronary artery disease and heart failure, when intensified by the detrimental effects of the severe acute respiratory syndrome coronavirus (SARS-CoV-2) over the endothelium, may explain their worse outcomes in COVID-19. ${ }^{30-33}$ Regarding obesity, a communitybased clinical trial $(\mathrm{n}=521$; mean follow-up of 8.5 years) showed that increases in weight, body mass index, waist circumference and body-fat percentage over time were associated with worsening of microvascular endothelial function, assessed by flow-mediated dilation in the brachial artery. ${ }^{34}$ Most subjects (84\%) were overweight or obese at baseline; those who lost weight over time had improved vascular endothelial function. ${ }^{34}$

In fact, vascular endothelial dysfunction and increased arterial stiffness are thought to contribute to a unfavorable response of the endothelium to the infection by SARS$\mathrm{CoV}-2$, whereas alterations in cardiac structure and function and the prothrombotic environment in obesity could provide a link for the augmented cardiovascular events in these patients. ${ }^{35}$ Moreover, fast increasing evidence from basic science, imaging and clinical observations suggest that COVID-19 could be considered as a vascular disease. $^{36,37}$

\section{Microvascular Endothelial Dysfunction}

Obesity is accompanied by functional and structural systemic microvascular dysfunction, ${ }^{38}$ and endothelialdependent microvascular vasodilation is severely impaired in obesity. ${ }^{39-41}$ Endothelial-dependent capillary recruitment, induced either by reactive hyperemia or by shear stress, is blunted in obese subjects, compared to non-obese counterparts. ${ }^{42,43}$ In the clinical setting, endothelial function and reactivity can be assessed using different technologies that evaluate microvascular flow and tissue perfusion coupled to physiological or pharmacological stimuli, ${ }^{44,45}$ to activate different vasodilator pathways resulting in increased microvascular conductance. The most commonly used provocations are the administration of endothelial-dependent vasodilators by transdermal iontophoresis, ${ }^{46-48}$ thermal hyperemia ${ }^{49,50}$ and postocclusive reactive hyperemia. ${ }^{51-53}$ In this context, the cutaneous microcirculation is now considered as an accessible and representative vascular bed for the assessment of systemic microcirculatory reactivity. ${ }^{45,54-56}$ A reduced vasodilation response to these different stimuli is indicative of microvascular endothelial dysfunction and is also considered to be predictive for cardiovascular and metabolic diseases and clinical prognosis. ${ }^{57-60}$

In patients with established cardiovascular disease, the reduction of microvascular endothelial-dependent vasodilation (ie, endothelial dysfunction) is associated with increasing BMI, even after adjustment for treated diabetes mellitus, hypertension, hypercholesterolemia, and smoking. ${ }^{61}$ In that study, BMI was classified in three different intervals: $<25$, 25-to 30 and $>30 \mathrm{~kg} / \mathrm{m}^{2}$. ${ }^{61}$ Moreover, Csipo et al showed that weight loss (reduction of BMI from 31.8 to $27.5 \mathrm{~kg} / \mathrm{m}^{2}$, accompanied by a reduction of serum cholesterol, LDL, triglycerides, and increased HDL) after a low-carbohydrate, low-calorie diet, resulted in improvement of microvascular endothelial function in geriatric obese (class 1) patients, ${ }^{62}$ assessed by laser speckle contrast imaging in the skin, after postocclusive reactive hyperemia. Additionally, endothelial function of resistance arterioles of the gluteal subcutaneous tissue is impaired in non-diabetic subjects with moderate levels of obesity (BMI $34.7 \pm 4.0 \mathrm{~kg} / \mathrm{m}^{2}$ ), in association with systemic inflammation. In women, BMI was significantly associated with high-sensitivity C-reactive protein. ${ }^{63}$

Regarding mechanisms of microvascular dysfunction, using a new methodology of microdialysis in the skeletal 
muscle, La Favor et al showed a significant increase in superoxide anions, as well as in NADPH oxidase subunit expression, associated with microvascular endothelial dysfunction in obese subjects relative to lean and overweight/ mildly obese subjects. ${ }^{64}$ Interestingly, 8 weeks of aerobic exercise training resulted in decreased $\mathrm{H}_{2} \mathrm{O}_{2}$ levels and improved microvascular endothelial function in the muscle tissue of obese subjects. ${ }^{64}$ The study therefore linked NADPH oxidase, as a source of reactive oxygen species, to microvascular endothelial dysfunction in obese individuals, with amelioration induced by aerobic exercise.

Microvascular dysfunction has been considered to be a pathophysiological link between overweight/obesity and cardiometabolic diseases, including arterial hypertension, insulin resistance, and glucose intolerance. ${ }^{43,65-69}$ Acknowledged mechanisms include changes in the secretion of adipokines, leading to increased levels of free fatty acids and inflammatory mediators, and decreased levels of adiponectin, all of which may impair endothelial insulin signaling. ${ }^{70-73}$ It is also of note that there are changes at the level of the microvascular network in obesity, involving a reduction in the number of arterioles or capillaries within vascular beds of various tissues (such as the skeletal muscle and skin), which is defined as vascular (capillary) rarefaction. ${ }^{74-77}$ In fact, obese individuals have both structural and functional alterations in skin microcirculation that are proportional to the increase in the degree of global and central obesity, arterial pressure levels and with the degree of insulin resistance. ${ }^{42}$ In non-diabetic, untreated hypertensive patients, reduced capillary density has also been related to obesity and other cardiometabolic risk factors. ${ }^{78}$ In addition, in adults and also in prepubertal children, visceral adiposity measured with magnetic resonance imaging is inversely associated with endothelialdependent skin capillary recruitment, and is accompanied by increased plasma levels of inflammatory markers. ${ }^{79}$

Impaired left ventricular diastolic function and higher risk of heart failure in obese individuals has been suggested to be associated with myocardial microvascular dysfunction. $^{80}$ In obese patients undergoing coronary artery bypass graft surgery, coronary microvascular density is significantly lower, compared to non-obese patients, and accompanied by increased body mass index and percent body fat together with increased left ventricular filling pressures. ${ }^{80}$ Moreover, in patients with suspected coronary artery disease, increasing body mass index is associated with reduced microvascular endothelial function, even after adjustment for treated diabetes mellitus, hypertension, hypercholesterolemia, and smoking. ${ }^{61}$ Interestingly, the study evaluated microvascular endothelial function three different technologies, including peripheral arterial tonometry, laser Doppler flowmetry and digital thermal monitoring. ${ }^{61}$

Reduced skeletal muscle capillary density and microvascular reactivity in obese subjects improved after 4 weeks of either sprint interval training, or moderate-intensity continuous training, together with increased endothelial eNOS content. ${ }^{81}$

It has also been shown that bariatric surgery improves microvascular dysfunction in obese patients who were free of metabolic syndrome after surgery, in association with postoperative increases in HDL-cholesterol levels and decreases in oxidized LDL levels. ${ }^{82}$

Another clinical study investigated microvascular endothelial function - using flow-mediated dilation in arterioles isolated from subcutaneous adipose tissue - in young women presenting with obesity (age: $33 \pm 2$ years, body mass index: $\left.33.0 \pm 0.6 \mathrm{~kg} / \mathrm{m}^{2}\right)$. ${ }^{83}$ The results showed that a 6-week low-carbohydrate diet, associated or not with caloric restriction, improve endothelial-dependent microvascular function through increases in nitric oxide bioavailability. ${ }^{83}$ On the other hand, this nutritional intervention did not affect macrovascular endothelial function, evaluated using brachial artery flow-mediated dilation. ${ }^{83}$

Regarding putative pathophysiological mechanisms, a study by Dimassi et $\mathrm{al}^{84}$ in young individuals with obesity (BMI $>30 \mathrm{~kg} / \mathrm{m}^{2}, \mathrm{n}=69$ ), compared with controls with normal weight, suggested that the expression of circulating microparticles containing endothelial nitric oxide synthase (eNOS) is significantly reduced in obesity individuals with endothelial-dependent microvascular dysfunction characterized using cutaneous laser Doppler flowmetry. ${ }^{84}$

\section{Multiple Pathways for COVID-I 9 Severity in Obese Patients}

Low-grade inflammation is the common feature that encompasses all the high-risk patients for developing severe COVID-19. Obesity is associated with a fivefold increased risk of developing SARS in SARS-CoV-2 infected individuals, and the well-documented increased susceptibility of obese patients to develop severe forms of COVID-19 may be linked to the elevated systemic metabolic inflammation in these patients. ${ }^{19}$ Metabolic alterations seen in obese and in diabetic patients are related to 
an inflammatory response, ${ }^{85,86}$ and several studies report elevated levels of circulating inflammatory cytokines such as TNF- $\alpha$, IL- $1 \beta$ and IL-6 in obese patients. ${ }^{87}$ Furthermore, visceral fat shows significant univariate association with the need for intensive care in COVID-19 patients, ${ }^{15}$ and deregulated expression of adipokines, such as leptin and resistin, increases the expression of vascular adhesion molecule 1 (VCAM-1) and intercellular adhesion molecule 1 (ICAM-1) that contribute to increased vascular leukocyte adhesiveness and additional oxidative stress. ${ }^{88}$ To further complicate the scenario, adipose-derived mesenchymal stem cell (ASCs), a specialized cell population in adipose tissue, are functionally compromised in obesity and changes its regulatory protective activity to a pro-inflammatory profile increasing its ability to secrete TNF- $\alpha$, IL- 8 , IL- 6 and MCP- $1 .{ }^{89,90}$ Therefore, ASCs from obese patients may not be able to modulate the immune response and tissue repair in SARS-CoV-2 infection contributing to more severe tissue injury. ${ }^{10}$

SARS-CoV-2 uses its viral spike (S) protein to invade target cells, such as epithelial cells, through binding to angiotensin-converting enzyme 2 (ACE2) after proteolytic activation by transmembrane protease serine 2 (TMPSS2). ${ }^{91}$ Others enzymes like furin, trypsin and elastase may also activate the $\mathrm{S}$ protein and facilitate cellular entry by the virus. ${ }^{92-94}$ Interestingly, adipose tissue highly expresses ACE2 and the expression is even higher in visceral adipose tissue. ${ }^{95}$ Of relevance, ACE2 expression is upregulated in obesity. ${ }^{96}$ Also, another suggested receptor for SARS-CoV-2, dipeptidyl peptidase 4 (DPP4), is expressed in adipose tissue and is upregulated in obesity. ${ }^{97,98}$ Finally, CD147, the alternative receptor for SARS-CoV-2, is positively correlated with an increase in body mass index. ${ }^{99}$ Taken together, the evidence of high expression of different SARS-CoV-2 receptors in adipose tissue may be the basis for increased severity of COVID19 in obese patients involving at least two different possibilities: First, infection of adipocytes with SARS-CoV-2 may exacerbate the innate immune response through pathogen recognition receptors in an already inflammation-primed tissue, increasing the magnitude of the response. Second, adipocytes may function as a reservoir for the SARS-CoV-2 and therefore may fuel the inflammatory response in adipose tissue and elsewhere in the organism by releasing viral NA and antigens that, by reaching the circulation generate ripple inflammatory effects across the organism. Importantly, these two possibilities are not mutually exclusive and may well combine their pathophysiological potential towards a deregulate systemic inflammatory response with widespread tissue injury and consequent organ dysfunction. It is important to add that as the pandemic evolves, new mechanistic interactions may unravel. For instance, new virus variants with mutations at the receptor-binding domain of the S protein may change the infectivity of the virus by changing its interactions with cellular receptors. In Brazil, a variant designated as $\mathrm{P} 1$, with multiple mutations in the $\mathrm{S}$ protein, was recently identified and is seemingly more infective than previous lineages of the virus. ${ }^{100}$ How this variant may interact with adipocytes increasing infectivity to these cells or potentiating the formation of an adipocyte reservoir of the virus causing a more severe disease in obese individuals is yet unknown. What is known is that a second wave caused by this new $\mathrm{P} 1$ variant is promoting devastating effects in Brazil with apparently higher mortality and a faster progression of the disease.

Severe COVID-19 is characterized by a massive production of pro-inflammatory mediators, in special cytokines. Frequently, the term "cytokine storm" is called up to describe the massive production of cytokines that occurs in viral infections (including SARS-CoV and MERS-CoV) , in sepsis and more recently, in severe COVID-19. ${ }^{101}$ Increased levels of IL-6, TNF- $\alpha$, IP10 are commonly found in patients with severe COVID-19. ${ }^{102}$ It is reasonable to propose that obese patients who already have an underlying chronic inflammation when infected with SARS-CoV-2 are prone to develop a more intense and deregulated response, and in doing so, developing a severe presentation of the disease. In addition, dysfunctional metabolism, endothelium, and overall immune response would further contribute to an unfavorable evolution of the disease in the obese patients. The questions about the molecular mechanisms behind this disproportional response remain unanswered, but our knowledge about this disease is growing in an unprecedented velocity and we may soon have the answer. However, a few possibilities may be put forward (Figure 1).

As stated above, obesity is characterized by the induction of a low-grade chronic proinflammatory state and $\mathrm{NF}-\mathrm{KB}$ is described as a key factor in the low-grade inflammation state in atherosclerosis and hypertension. ${ }^{103,104}$ Also, the NF-kB pathway is involved in insulin resistance, a condition frequently seen in obese patients, and in $\beta$-cell dysfunction. ${ }^{105}$ In addition, free fatty acids can also promote inflammation and activate the NF- $\mathrm{KB}$ and JNK1 pathways. ${ }^{106}$ All those pieces put 
together may point to NF- $\mathrm{B}$ being a key player in obese patients with COVID-19. Importantly, cell culture experiments combined with system biology approach showed that overexpression of Nsp1 during infection with SARS$\mathrm{CoV}-2$ strongly increases signaling through the nuclear factor of activated T cells (NFAT) and increases cytokine production and immune-dependent pathogenesis. Both NF- $\mathrm{kB}$ and NFAT pathways share common regulation signals, such as Foxp3 and Foxd1, and a similar mechanism of activation against infection. ${ }^{107}$

We must also consider that binding of SARS-CoV-2 to ACE2 leads to receptor internalization and high cytosolic levels of angiotensin II, which is a recognized activator of NLP3 inflammasome in the lung ${ }^{108}$ and other tissues. The NLRP3 inflammasome regulates pyroptosis through gasdermin $\mathrm{D}$, along with the release of cytosolic contents into the extracellular spaces. The release of alarmins, ATP, ROS, cytokines, chemokines, LDH and viral particles elicits an immediate reaction from surrounding immune cells, inducing a pyroptotic triggered reaction further fueling inflammation. Interestingly, different studies have reported elevated levels of LDH, a cytosolic enzyme that is measured for monitoring pyroptosis in patients with the severe form of COVID-19. ${ }^{109}$ On the other hand, dietinduced alterations in the gut leading to increased gut permeability to bacterial endotoxins are known to promote activation of NLRP3 inflammasomes via Toll-like receptors (TLRs). This event is followed by the accumulation of IL-1 family cytokines, which modulate insulin production by pancreatic beta cells. ${ }^{110}$ Importantly and at the same time, a decrease in endogenous protective mechanisms occurs. ${ }^{111}$ NLRP3 inflammasome activation is involved in endothelial lysosome membrane permeabilization, cathepsin B release, and impaired glycocalyx thickness, ${ }^{112}$ thus further contributing to the endothelial cell dysfunction, enhanced susceptibility to cardiovascular injury and thrombotic events, a common complication in severe COVID-19 patients.

In fact, thrombotic events are now recognized as a common feature in COVID-19 patients, and COVID-19 has recently been suggested to be a thrombotic viral fever. ${ }^{113}$ Obese patients are prone to thrombotic events for many different reasons, ${ }^{113}$ and COVID-19 may contribute even further to this complication. The imbalance of the ACE/ ACE2 system caused by internalization of ACE2 after binding to virus $S$ protein causes a switch towards pro-thrombotic activity by decreasing Ang-(1-7)-Mas axis (antithrombotic) and increasing angiotensin II (prothrombotic). This mechanism may be of central pathogenic relevance explaining the poor outcome of obese patients with COVID-19. ${ }^{113}$

In summary, there are many different ways by which low-grade inflammation caused by metabolic changes in obesity may contribute to the worse prognosis of obese patients infected by SARS-CoV-2, in a combination of factors and mechanisms leading to a subversion of the defensive responses of the organism against the virus.

\section{Disclosure}

The authors report no conflicts of interest in this work.

\section{References}

1. Nicklas TA, O'Neil CE. Prevalence of obesity: a public health problem poorly understood. AIMS Public Heal. 2014;1 (2):109-122. doi:10.3934/publichealth.2014.2.109

2. Wu Z, McGoogan JM. Characteristics of and important lessons from the coronavirus Disease 2019 (COVID-19) outbreak in China: summary of a report of 72314 cases from the Chinese center for disease control and prevention. JAMA - J Am Med Assoc. 2020;323(13):1239-1242. doi:10.1001/jama.2020.2648

3. Docherty AB, Harrison EM, Green CA, et al. Features of 20133 UK patients in hospital with covid-19 using the ISARIC WHO clinical characterisation protocol: prospective observational cohort study. BMJ. 2020;369. doi:10.1136/bmj.m1985

4. Petrilli CM, Jones SA, Yang J, et al. Factors associated with hospital admission and critical illness among 5279 people with coronavirus disease 2019 in New York city: prospective cohort study. BMJ. 2020;369. doi:10.1136/bmj.m1966

5. Hernández-Garduño E. Obesity is the comorbidity more strongly associated for Covid-19 in Mexico. A case-control study. Obes Res Clin Pract. 2020;14(4):375-379. doi:10.1016/j. orcp.2020.06.001

6. Hajifathalian K, Kumar S, Newberry C, et al. Obesity is associated with worse outcomes in COVID-19: analysis of early data from New York city. Obesity. 2020;28(9):1606-1612. doi:10.1002/oby.22923

7. Busetto L, Bettini S, Fabris R, et al. Obesity and COVID-19: an Italian snapshot. Obesity. 2020;28(9):1600-1605. doi:10.1002/ oby. 22918

8. Hussain A, Mahawar K, Xia Z, Yang W, EL-Hasani S. Obesity and mortality of COVID-19. Meta-analysis. Obes Res Clin Pract. 2020;14(4):295-300. doi:10.1016/j.orcp.2020.07.002

9. Klöting N, Blüher M. Adipocyte dysfunction, inflammation and metabolic syndrome. Rev Endocr Metab Disord. 2014;15 (4):277-287. doi:10.1007/s11154-014-9301-0

10. Louwen F, Ritter A, Kreis NN, Yuan J. Insight into the development of obesity: functional alterations of adipose-derived mesenchymal stem cells. Obes Rev. 2018;19(7):888-904. doi:10.1111/obr.12679

11. Febbraio MA. Role of interleukins in obesity: implications for metabolic disease. Trends Endocrinol Metab. 2014;25 (6):312-319. doi:10.1016/j.tem.2014.02.004

12. Huttunen R, Syrjänen J. Obesity and the risk and outcome of infection. Int $J$ Obes. 2013;37(3):333-340. doi:10.1038/ ijo. 2012.62

13. Ghilotti F, Bellocco R, Ye W, Adami HO, Trolle Lagerros Y. Obesity and risk of infections: results from men and women in the Swedish National March Cohort. Int J Epidemiol. 2019;48 (6):1783-1794. doi:10.1093/ije/dyz129 
14. Honce R, Schultz-Cherry S. Impact of obesity on influenza A virus pathogenesis, immune response, and evolution. Front Immunol. 2019;10. doi:10.3389/fimmu.2019.01071

15. Hill JH, Solt C, Foster MT. Obesity associated disease risk: the role of inherent differences and location of adipose depots. Horm Mol Biol Clin Investig. 2018;33(2). doi:10.1515/hmbci-20180012

16. Huh JY, Park YJ, Ham M, Kim JB. Crosstalk between adipocytes and immune cells in adipose tissue inflammation and metabolic dysregulation in obesity. Mol Cells. 2014;37(5):365-371. doi:10.14348/molcells.2014.0074

17. Cildir G, Akincilar SC, Tergaonkar V. Chronic adipose tissue inflammation: all immune cells on the stage. Trends Mol Med. 2013;19(8):487-500. doi:10.1016/j.molmed.2013.05.001

18. Poblete JMS, Ballinger MN, Bao S, et al. Macrophage HIF-1 $\alpha$ mediates obesity-related adipose tissue dysfunction via interleukin-1 receptor-associated kinase M. Am J Physiol - Endocrinol Metab. 2020;318(5):E689-E700. doi:10.1152/ajpendo. 00174.2019

19. Wani K, AlHarthi H, Alghamdi A, Sabico S, Al-Daghri NM. Role of NLRP3 inflammasome activation in obesity-mediated metabolic disorders. Int J Environ Res Public Health. 2021;18(2):511. doi:10.3390/ijerph18020511

20. Woo C-Y, Jang JE, Lee SE, Koh EH, Lee K-U. Mitochondrial dysfunction in adipocytes as a primary cause of adipose tissue inflammation. Diabetes Metab J. 2019;43:247. doi:10.4093/ dmj.2018.0221

21. Cui H, López M, Rahmouni K. The cellular and molecular bases of leptin and ghrelin resistance in obesity. Nat Rev Endocrinol. 2017;13(6):338-351. doi:10.1038/nrendo.2016.222

22. Vadde R, Gupta MK, Nagaraju GP. Is adipose tissue an immunological organ? Crit Rev Immunol. 2019;39(6):481-490. doi:10.1615/CritRevImmunol.2020033457

23. Russo L, Lumeng CN. Properties and functions of adipose tissue macrophages in obesity. Immunology. 2018;155(4):407-417. doi:10.1111/imm.13002

24. Becker M, Pinhasov A, Ornoy A. Animal models of depression: what can they teach us about the human disease? Diagnostics. 2021;11(1):123. doi:10.3390/diagnostics 11010123

25. Décarie-Spain L, Sharma S, Hryhorczuk C, et al. Nucleus accumbens inflammation mediates anxiodepressive behavior and compulsive sucrose seeking elicited by saturated dietary fat. Mol Metab. 2018;10:1-13. doi:10.1016/j.molmet.2018.01.018

26. Li B, Leung JCK, Chan LYY, Yiu WH, Tang SCW. A global perspective on the crosstalk between saturated fatty acids and Toll-like receptor 4 in the etiology of inflammation and insulin resistance. Prog Lipid Res. 2020;77. doi:10.1016/j. plipres.2019.101020

27. Taniguchi K, Karin M. NF-B, inflammation, immunity and cancer: coming of age. Nat Rev Immunol. 2018;18(5):309-324. doi:10.1038/nri.2017.142

28. Zhang Q, Lenardo MJ, Baltimore D. 30 years of NF-кB: a blossoming of relevance to human pathobiology. Cell. 2017;168(1-2):37-57. doi:10.1016/j.cell.2016.12.012

29. Aboudounya MM, Heads RJ. COVID-19 and toll-like receptor 4 (TLR4): SARS-CoV-2 may bind and activate TLR4 to increase ACE2 expression, facilitating entry and causing hyperinflammation. 2021. doi:10.1155/2021/8874339.

30. Nägele MP, Haubner B, Tanner FC, Ruschitzka F, Flammer AJ. Endothelial dysfunction in COVID-19: current findings and therapeutic implications. Atherosclerosis. 2020;314:58-62. doi:10.1016/j.atherosclerosis.2020.10.014

31. De Lorenzo A, Escobar S, Tibiriçá E. Systemic endothelial dysfunction: a common pathway for COVID-19, cardiovascular and metabolic diseases. Nutr Metab Cardiovasc Dis. 2020;30 (8):1401-1402. doi:10.1016/j.numecd.2020.05.007
32. Del Turco S, Vianello A, Ragusa R, Caselli C, Basta G. COVID19 and cardiovascular consequences: is the endothelial dysfunction the hardest challenge? Thromb Res. 2020;196:143-151. doi:10.1016/j.thromres.2020.08.039

33. Hayden MR. Endothelial activation and dysfunction in metabolic syndrome, type 2 diabetes and coronavirus disease 2019. $J$ Int Med Res. 2020;48(7):030006052093974. doi:10.1177/ 0300060520939746

34. Coutinho T, Turner ST, Kullo IJ. Adverse effects of long-term weight gain on microvascular endothelial function. Obes Res Clin Pract. 2018;12(5):452-458. doi:10.1016/j.orcp.2018.06.008

35. Korakas E, Ikonomidis I, Kousathana F, et al. Obesity and COVID-19: immune and metabolic derangement as a possible link to adverse clinical outcomes. Am J Physiol - Endocrinol Metab. 2020;319(1):E105-E109. doi:10.1152/ajpendo. 00198.2020

36. Siddiqi HK, Libby P, Ridker PM. COVID-19 - a vascular disease. Trends Cardiovasc Med. 2021;31(1):1-5. doi:10.1016/j. tcm.2020.10.005

37. Levy JH, Iba T, Connors JM. Editorial commentary: vascular injury in acute infections and COVID-19: everything old is new again. Trends Cardiovasc Med. 2021;31(1):6-7. doi:10.1016/j. tcm.2020.10.011

38. Virdis A, Masi S, Colucci R, et al. Microvascular endothelial dysfunction in patients with obesity. Curr Hypertens Rep. 2019;21(4). doi:10.1007/s11906-019-0930-2

39. Houben AJHM, Martens RJH, Stehouwer CDA. Assessing microvascular function in humans from a chronic disease perspective. $J$ Am Soc Nephrol. 2017;28(12):3461-3472. doi:10.1681/ ASN.2017020157

40. Jonk AM, Houben AJHM, De Jongh RT, Serné EH, Schaper NC, Stehouwer CDA. Microvascular dysfunction in obesity: a potential mechanism in the pathogenesis of obesity-associated insulin resistance and hypertension. Physiology. 2007;22 (4):252-260. doi:10.1152/physiol.00012.2007

41. Boillot A, Zoungas S, Mitchell P, et al. Obesity and the microvasculature: a systematic review and meta-analysis. PLoS One. 2013;8:2. doi:10.1371/journal.pone.0052708

42. Francischetti EA, Tibirica E, Da Silva EG, Rodrigues E, Celoria BM, De Abreu VG. Skin capillary density and microvascular reactivity in obese subjects with and without metabolic syndrome. Microvasc Res. 2011;81(3):325-330. doi:10.1016/j. mvr.2011.01.002

43. Karaca Ü, Schram MT, Houben AJHM, Muris DMJ, Stehouwer CDA. Microvascular dysfunction as a link between obesity, insulin resistance and hypertension. Diabetes Res Clin Pract. 2014;103(3):382-387. doi:10.1016/j.diabres.2013.12.012

44. Roustit M, Cracowski JL. Assessment of endothelial and neurovascular function in human skin microcirculation. Trends Pharmacol Sci. 2013;34(7):373-384. doi:10.1016/j. tips.2013.05.007

45. Cracowski JL, Roustit M. Current methods to assess human cutaneous blood flow: an updated focus on laser-basedtechniques. Microcirculation. 2016;23(5):337-344. doi:10.1111/ micc. 12257

46. Barata Kasal DA, Britto A, Verri V, De Lorenzo A, Tibirica E. Systemic microvascular endothelial dysfunction is associated with left ventricular ejection fraction reduction in chronic Chagas disease patients. Microcirculation. 2021;28:e12664. doi: $10.1111 /$ micc. 12664

47. Verri V, Nascimento AR, Brandao AA, Tibirica E. Effects of chronic type 5 phosphodiesterase inhibition on penile microvascular reactivity in hypertensive patients with erectile dysfunction: a randomized crossover placebo-controlled trial. $J$ Hum Hypertens. 2021;35(4):360-370. doi:10.1038/s41371-020-0343-3 
48. Matheus ASM, Maria de Fátima B, Clemente EL, et al. Sensibility and specificity of laser speckle contrast imaging according to Endo-PAT index in type 1 diabetes. Microvasc Res. 2018;117:10-15. doi:10.1016/j.mvr.2017.11.002

49. Salgado MAM, Salgado-Filho MF, Reis-Brito JO, Lessa MA, Tibirica E. Effectiveness of laser Doppler perfusion monitoring in the assessment of microvascular function in patients undergoing on-pump coronary artery bypass grafting. $J$ Cardiothorac Vasc Anesth. 2014;28(5):1211-1216. doi:10.1053/j. jvca.2014.03.003

50. de Moraes R, Van Bavel D, de Brito Gomes M, Tibiriçá E. Effects of non-supervised low intensity aerobic exercise training on the microvascular endothelial function of patients with type 1 diabetes: a non-pharmacological interventional study. $B M C$ Cardiovasc Disord. 2016;16(1). doi:10.1186/s12872-016-0191-9

51. Varsamis P, Walther G, Share B, et al. Transient endothelial dysfunction induced by sugar-sweetened beverage consumption may be attenuated by a single bout of aerobic exercise. Microvasc Res. 2018;115:8-11. doi:10.1016/j.mvr.2017.07.003

52. Hellmann M, Roustit M, Gaillard-Bigot F, Cracowski JL. Cutaneous iontophoresis of treprostinil, a prostacyclin analog, increases microvascular blood flux in diabetic malleolus area. Eur $J \quad$ Pharmacol. 2015;758:123-128. doi:10.1016/j. ejphar.2015.03.066

53. Cordovil I, Huguenin G, Rosa G, et al. Evaluation of systemic microvascular endothelial function using laser speckle contrast imaging. Microvasc Res. 2012;83(3):376-379. doi:10.1016/j. mvr.2012.01.004

54. Holowatz LA, Thompson-Torgerson CS, Kenney WL. The human cutaneous circulation as a model of generalized microvascular function. J Appl Physiol. 2008;105(1):370-372. doi:10.1152/ japplphysiol.00858.2007

55. Iredahl F, Löfberg A, Sjöberg F, Farnebo S, Tesselaar E. Noninvasive measurement of skin microvascular response during pharmacological and physiological provocations. PLoS One. 2015;10(8):e0133760. doi:10.1371/journal.pone.0133760

56. Tur E, Yosipovitch G, Bar-On Y. Skin reactive hyperemia in diabetic patients: a study by laser Doppler flowmetry. Diabetes Care. 1991;14(11):958-962. doi:10.2337/diacare.14.11.958

57. IJzerman RG, De Jongh RT, Beijk MAM, et al. Individuals at increased coronary heart disease risk are characterized by an impaired microvascular function in skin. Eur $J$ Clin Invest. 2003;33(7):536-542. doi:10.1046/j.1365-2362.2003.01179.x

58. Yamamoto-Suganuma R, Aso Y. Relationship between post-occlusive forearm skin reactive hyperaemia and vascular disease in patients with Type 2 diabetes - A novel index for detecting micro- and macrovascular dysfunction using laser Doppler flowmetry. Diabet Med. 2009;26(1):83-88. doi:10.1111/ j.1464-5491.2008.02609.x

59. Ijzerman RG, Serne EH, Van Weissenbruch MH, De Jongh RT, Stehouwer CDA. Cigarette smoking is associated with an acute impairment of microvascular function in humans. Clin Sci. 2003;104(3):247-252. doi:10.1042/CS20020318

60. Halcox JPJ, Schenke WH, Zalos G, et al. Prognostic value of coronary vascular endothelial dysfunction. Circulation. 2002;106 (6):653-658. doi:10.1161/01.CIR.0000025404.78001.D8

61. van der Heijden DJ, van Leeuwen MAH, Janssens GN, et al. Body mass index is associated with microvascular endothelial dysfunction in patients with treated metabolic risk factors and suspected coronary artery disease. $J$ Am Heart Assoc. 2017;6(9). doi:10.1161/JAHA.117.006082

62. Csipo T, Fulop GA, Lipecz A, et al. Short-term weight loss reverses obesity-induced microvascular endothelial dysfunction. GeroScience. 2018;40(3):337-346. doi:10.1007/s11357-0180028-9
63. Suboc TMB, Dharmashankar K, Wang J, et al. Moderate obesity and endothelial dysfunction in humans: influence of gender and systemic inflammation. Physiol Rep. 2013;1:3. doi:10.1002/ phy 2.58

64. La Favor JD, Dubis GS, Yan H, et al. Microvascular endothelial dysfunction in sedentary, obese humans is mediated by NADPH oxidase: influence of exercise training. Arterioscler Thromb Vasc Biol. 2016;36(12):2412-2420. doi:10.1161/ ATVBAHA.116.308339

65. Serné EH, De Jongh RT, Eringa EC, IJzerman RG, Stehouwer CDA. Microvascular dysfunction: a potential pathophysiological role in the metabolic syndrome. Hypertension. 2007;50:204-211.

doi:10.1161/ HYPERTENSIONAHA.107.089680

66. Serné EH, Stehouwer CDA, Ter Maaten JC, et al. Microvascular function relates to insulin sensitivity and blood pressure in normal subjects. Circulation. 1999;99(7):896-902. doi:10.1161/01. CIR.99.7.896

67. De Jongh RT, Serné EH, Ijzerman RG, De Vries G, Stehouwer CDA. Impaired microvascular function in obesity: implications for obesity-associated microangiopathy, hypertension, and insulin resistance. Circulation. 2004;109 (21):2529-2535. doi:10.1161/01.CIR.0000129772.26647.6F

68. Serné EH, DeJongh RT, Eringa EC, Ijzerman RG, DeBoer MP, Stehouwer CDA. Microvascular dysfunction: causative role in the association between hypertension, insulin resistance and the metabolic syndrome? Essays Biochem. 2006;42:163-176. doi:10.1042/bse0420163

69. Rattigan S, Bussey CT, Ross RM, Richards SM. Obesity, insulin resistance, and capillary recruitment. Microcirculation. 2007;14 (4-5):299-309. doi:10.1080/10739680701282796

70. Yudkin JS, Eringa E, Stehouwer CDA. "Vasocrine" signalling from perivascular fat: a mechanism linking insulin resistance to vascular disease. Lancet. 2005;365(9473):1817-1820. doi:10.1016/S0140-6736(05)66585-3

71. De Jongh RT, Serné EH, Ijzerman RG, De Vries G, Stehouwer CDA. Free fatty acid levels modulate microvascular function: relevance for obesity-associated insulin resistance, hypertension, and microangiopathy. Diabetes. 2004;53 (11):2873-2882. doi:10.2337/diabetes.53.11.2873

72. Ijzerman RG, Voordouw JJ, Van Weissenbruch MM, et al. TNF- $\alpha$ levels are associated with skin capillary recruitment in humans: a potential explanation for the relationship between TNF- $\alpha$ and insulin resistance. Clin Sci. 2006;110(3):361-368. doi:10.1042/ CS20050314

73. Cheng C, Daskalakis C. Association of adipokines with insulin resistance, microvascular dysfunction, and endothelial dysfunction in healthy young adults. Mediators Inflamm. 2015;2015:1-9. doi: $10.1155 / 2015 / 594039$

74. Levy BI, Ambrosio G, Pries AR, Struijker-Boudier HAJ. Microcirculation in hypertension: a new target for treatment? Circulation. 2001;104(6):735-740. doi:10.1161/hc3101.091158

75. Serné EH, Gans ROB, Ter Maaten JC, Tangelder GJ, Donker AJM, Stehouwer CDA. Impaired skin capillary recruitment in essential hypertension is caused by both functional and structural capillary rarefaction. Hypertension. 2001;38 (2):238-242. doi:10.1161/01.HYP.38.2.238

76. Serné EH, Gans ROB, Ter Maaten JC, Ter Wee PM, Donker AJM, Stehouwer CDA. Capillary recruitment is impaired in essential hypertension and relates to insulin's metabolic and vascular actions. Cardiovasc Res. 2001;49(1):161-168. doi:10.1016/S0008-6363(00)00198-X

77. Clerk LH, Vincent MA, Jahn LA, Liu Z, Lindner JR, Barrett EJ. Obesity blunts insulin-mediated microvascular recruitment in human forearm muscle. Diabetes. 2006;55(5):1436-1442. doi: $10.2337 / \mathrm{db} 05-1373$ 
78. Debbabi H, Uzan L, Mourad JJ, Safar M, Levy BI, Tibirica TE. Increased skin capillary density in treated essential hypertensive patients. Am J Hypertens. 2006;19(5):477-483. doi:10.1016/j. amjhyper.2005.10.021

79. De Jongh RT, Ijzerman RG, Serne EH, et al. Visceral and truncal subcutaneous adipose tissue are associated with impaired capillary recruitment in healthy individuals. J Clin Endocrinol Metab. 2006;91(12):5100-5106. doi:10.1210/jc.2006-1103

80. Campbell DJ, Somaratne JB, Prior DL, et al. Obesity is associated with lower coronary microvascular density. PLoS One. 2013;8 (11):e81798. doi:10.1371/journal.pone.0081798

81. Cocks M, Shaw CS, Shepherd SO, et al. Sprint interval and moderate-intensity continuous training have equal benefits on aerobic capacity, insulin sensitivity, muscle capillarisation and endothelial eNOS/NAD $(\mathrm{P}) \mathrm{H}$ oxidase protein ratio in obese men. $J \quad$ Physiol. 2016;594(8):2307-2321. doi:10.1113/ jphysiol.2014.285254

82. Martín-Rodríguez JF, Cervera-Barajas A, Madrazo-Atutxa A, et al. Effect of bariatric surgery on microvascular dysfunction associated to metabolic syndrome: a 12-month prospective study. Int $J$ Obes. 2014;38(11):1410-1415. doi:10.1038/ ijo. 2014.15

83. Hwang C-L, Ranieri C, Szczurek MR, et al. The effect of low-carbohydrate diet on macrovascular and microvascular endothelial function is not affected by the provision of caloric restriction in women with obesity: a randomized study. Nutrients. 2020;12(6):1649. doi:10.3390/nu12061649

84. Dimassi S, Chahed K, Boumiza S, et al. Role of eNOS- and NOX-containing microparticles in endothelial dysfunction in patients with obesity. Obesity. 2016;24(6):1305-1312. doi:10.1002/oby.21508

85. Mastrocola R, Penna C, Tullio F, et al. Pharmacological inhibition of NLRP3 inflammasome attenuates myocardial ischemia/reperfusion injury by activation of RISK and mitochondrial pathways. Oxid Med Cell Longev. 2016;2016:1-11. doi:10.1155/2016/ 5271251

86. Hotamisligil GS. Inflammation, metaflammation and immunometabolic disorders. Nature. 2017;542(7640):177-185. doi:10.1038/ nature21363

87. Huang C, Wang Y, Li X, et al. Clinical features of patients infected with 2019 novel coronavirus in Wuhan, China. Lancet. 2020;395(10223):497-506. doi:10.1016/S0140-6736(20)30183-5

88. Ballak DB, Stienstra R, Tack CJ, Dinarello CA, van Diepen JA. IL-1 family members in the pathogenesis and treatment of metabolic disease: focus on adipose tissue inflammation and insulin resistance. Cytokine. 2015;75(2):280-290. doi:10.1016/j. cyto.2015.05.005

89. Ritter A, Kreis NN, Roth S, et al. Restoration of primary cilia in obese adipose-derived mesenchymal stem cells by inhibiting Aurora A or extracellular signal-regulated kinase. Stem Cell Res Ther. 2019;10(1):255. doi:10.1186/s13287-019-1373-z

90. Lee MJ, Kim J, Kim MY, et al. Proteomic analysis of tumor necrosis factor- $\alpha$-induced secretome of human adipose tissuederived mesenchymal stem cells. J Proteome Res. 2010;9 (4):1754-1762. doi:10.1021/pr900898n

91. Hoffmann M, Kleine-Weber H, Schroeder S, et al. SARS-CoV-2 cell entry depends on ACE2 and TMPRSS2 and is blocked by a clinically proven protease inhibitor. Cell. 2020;181(2):271-280. e8. doi:10.1016/j.cell.2020.02.052

92. Millet JK, Whittaker GR. Host cell proteases: critical determinants of coronavirus tropism and pathogenesis. Virus Res. 2015;202:120-134. doi:10.1016/j.virusres.2014.11.021

93. Mille JK, Whittaker GR. Host cell entry of Middle East respiratory syndrome coronavirus after two-step, furin-mediated activation of the spike protein. Proc Natl Acad Sci U S A. 2014;111 (42):15214-15219. doi:10.1073/pnas.1407087111
94. Hoffmann M, Kleine-Weber H, Pöhlmann S. A multibasic cleavage site in the spike protein of SARS-CoV-2 is essential for infection of human lung cells. Mol Cell. 2020;78(4):779-784.e5. doi:10.1016/j.molcel.2020.04.022

95. Fu J, Zhou B, Zhang L, et al. Expressions and significances of the angiotensin-converting enzyme 2 gene, the receptor of SARS-CoV-2 for COVID-19. Mol Biol Rep. 2020;47 (6):4383-4392. doi:10.1007/s11033-020-05478-4

96. Gupte M, Boustany-Kari CM, Bharadwaj K, et al. ACE2 is expressed in mouse adipocytes and regulated by a high-fat diet. Am J Physiol - Regul Integr Comp Physiol. 2008;295(3):781-788. doi:10.1152/ajpregu.00183.2008

97. Li Y, Zhang Z, Yang L, et al. The MERS-CoV receptor DPP4 as a candidate binding target of the SARS-CoV-2 spike. iScience. 2020;23(6):101160. doi:10.1016/j.isci.2020.101400

98. Yanagimachi T, Fujita Y, Takeda Y, et al. Dipeptidyl peptidase-4 inhibitor treatment induces a greater increase in plasma levels of bioactive GIP than GLP-1 in non-diabetic subjects. Mol Metab. 2017;6(2):226-231. doi:10.1016/j.molmet.2016.12.009

99. Radzikowska U, Ding M, Tan G, et al. Distribution of ACE2, CD147, CD26, and other SARS-CoV-2 associated molecules in tissues and immune cells in health and in asthma, COPD, obesity, hypertension, and COVID-19 risk factors. Allergy. 2020;75 (11):2829-2845. doi:10.1111/all.14429

100. Resende PC, Gräf T, Acd P, et al. A potential SARS-CoV-2 variant of interest (VOI) harboring mutation E484K in the spike protein was identified within lineage B.1.1.33 circulating in Brazil. Viruses. 2021;13(5):724. doi:10.3390/v13050724

101. Coperchini F, Chiovato L, Croce L, Magri F, Rotondi M. The cytokine storm in COVID-19: an overview of the involvement of the chemokine/chemokine-receptor system. Cytokine Growth Factor Rev. 2020;53:25-32. doi:10.1016/j.cytogfr.2020.05.003

102. Chen G, Wu D, Guo W, et al. Clinical and immunological features of severe and moderate coronavirus disease 2019. J Clin Invest. 2020;130(5):2620-2629. doi:10.1172/JCI137244

103. Sun HJ, Ren XS, Xiong XQ, et al. NLRP3 inflammasome activation contributes to VSMC phenotypic transformation and proliferation in hypertension. Cell Death Dis. 2017;8(10):e3074. doi:10.1038/cddis.2017.470

104. Yu XH, Zheng XL, Tang CK. Nuclear factor- $\kappa B$ activation as a pathological mechanism of lipid metabolism and atherosclerosis. Adv Clin Chem. 2015;70:1-30. doi:10.1016/bs. acc.2015.03.004

105. Meyerovich K, Ortis F, Cardozo AK. The non-canonical NF-kB pathway and its contribution to $\beta$-cell failure in diabetes. $J \mathrm{Mol}$ Endocrinol. 2018;61(2):F1-F6. doi:10.1530/JME-16-0183

106. Shi H, Kokoeva MV, Inouye K, Tzameli I, Yin H, Flier JS. TLR4 links innate immunity and fatty acid-induced insulin resistance. J Clin Invest. 2006;116(11):3015-3025. doi:10.1172/JCI28898

107. Pfefferle S, Schöpf J, Kögl M, et al. The SARS-coronavirus-host interactome: identification of cyclophilins as target for pan-coronavirus inhibitors. PLoS Pathog. 2011;7(10):e1002331. doi:10.1371/journal.ppat.1002331

108. Meng Y, Pan M, Zheng B, et al. Autophagy attenuates angiotensin II-induced pulmonary fibrosis by inhibiting redox imbalance-mediated NOD-like receptor family pyrin domain containing 3 inflammasome activation. Antioxid Redox Signal. 2019;30(4):520-541. doi:10.1089/ars.2017.7261

109. Lippi G, Mattiuzzi C, Bovo C, Plebani M. Current laboratory diagnostics of coronavirus disease 2019 (COVID-19). Acta Biomed. 2020;91(2):137-145. doi:10.23750/abm.v91i2.9548

110. Tack CJ, Stienstra R, Joosten LAB, Netea MG. Inflammation links excess fat to insulin resistance: the role of the interleukin-1 family. Immunol Rev. 2012;249(1):239-252. doi:10.1111/j.1600-065X.2012.01145.x 
111. Mastrocola R, Collino M, Penna C, et al. Maladaptive modulations of nlrp3 inflammasome and cardioprotective pathways are involved in diet-induced exacerbation of myocardial ischemia/ reperfusion injury in mice. Oxid Med Cell Longev. 2016;2016:1-12. doi:10.1155/2016/3480637

112. Ikonomidis I, Pavlidis G, Katsimbri P, et al. Differential effects of inhibition of interleukin 1 and 6 on myocardial, coronary and vascular function. Clin Res Cardiol. 2019;108(10):1093-1101. doi:10.1007/s00392-019-01443-9
113. Costa-Filho RC, Castro-Faria Neto HC, Mengel J et al. Memórias do Instituto Oswaldo Cruz - 0552 Should COVID-19 be branded to Viral Thrombotic Fever? Published 2021. Available from: https://memorias.ioc.fiocruz.br/article/10804/0552-should-covid -19-be-branded-to-viral-thrombotic-fever. Accessed April 30, 2021.

\section{Publish your work in this journal}

The Journal of Inflammation Research is an international, peerreviewed open-access journal that welcomes laboratory and clinical findings on the molecular basis, cell biology and pharmacology of inflammation including original research, reviews, symposium reports, hypothesis formation and commentaries on: acute/chronic inflammation; mediators of inflammation; cellular processes; molecular mechanisms; pharmacology and novel anti-inflammatory drugs; clinical conditions involving inflammation. The manuscript management system is completely online and includes a very quick and fair peerreview system. Visit http://www.dovepress.com/testimonials.php to read real quotes from published authors. 